\title{
Uso do Rituximabe para o Tratamento da Plaquetopenia do Lúpus Eritematoso Sistêmico: Eficácia Clínica e Efeito nas Moléculas de Co-Estimulação
}

\section{Use of Rituximab for the Treatment of Systemic Lupus Erythematosus' Thrombocytopenia: Clinical Efficacy and Costimulatory Molecules Effect}

\author{
Mittermayer B. Santiago ${ }^{(1)}$, Eliana A. G. Reis ${ }^{(2)}$, Isabella Lima( ${ }^{(1)}$ Mitermayer G. Reis $^{(2)}$
}

\begin{abstract}
RESUMO
Plaquetopenia é uma complicação não raramente vista no contexto do lúpus eritematoso sistêmico (LES). O seu tratamento inclui o uso de corticosteróide, imunossupressores, imunoglobulina humana e, eventualmente, esplenectomia. Descreve-se um caso de LES com plaquetopenia persistente a despeito do uso de prednisona e azatioprina, que respondeu satisfatoriamente ao uso de rituximabe (RTX). O estudo de citometria de fluxo mostrou depleção dos linfócitos B do sangue periférico, assim como uma queda das moléculas de co-estimulação após o uso da medicação. Não foi observado efeito colateral relacionado à infusão da substância. Dessa forma, o RTX parece estar indicado para casos selecionados de LES com plaquetopenia de difícil controle.
\end{abstract}

Palavras-chave: lúpus eritematoso sistêmico, plaquetopenia, rituximabe, anti-CD20.

\section{INTRODUÇÃO}

O lúpus eritematoso sistêmico (LES) se caracteriza por uma alteração do sistema imunológico, com hiper-reativação dos linfócitos T CD4 e ativação policlonal de linfócitos B e assim produção de auto-anticorpos contra diversos antígenos. Clinicamente, a sua expressão e gravidade vão depender do (s) órgão (s) envolvido (s).

Plaquetopenia é uma manifestação comum no LES e seu tratamento classicamente inclui o uso de corticosteróides, imunossupressores, imunoglobulina humana e, eventual-

\begin{abstract}
Thrombocytopenia is not a rare complication in patients with systemic lupus erythematosus (SLE). Its treatment includes the use of corticosteroids, immunosuppressive drugs, intravenous immunoglobulin and, eventually, splenectomy. We describe a SLE patient with persistent thrombocytopenia despite of the use of prednisone and azathioprine that improved after infusion of rituximab (RTX). Flow cytometry analysis revealed depletion of B cells from the peripheral blood as well as a decrease in costimulatory molecules after the administration of the medication. Side effects related to the infusion were not observed. It suggests that $R T X$ may be indicated in selected cases of SLE with thrombocytopenia of difficult control.
\end{abstract}

Keywords: Systemic lupus erythematosus, thrombocytopenia, rituximab, anti-CD20.

mente, esplenectomia. Mais recentemente, com a introdução da terapia biológica em reumatologia, têm sido publicados alguns relatos do uso do anticorpo monoclonal anti-CD20 (rituximabe) para o tratamento dessa condição clínica, assim como para outras complicações do LES, como nefrite refratária, anemia hemolítica auto-imune e envolvimento do sistema nervoso central. Nossa experiência com o uso dessa medicação em doenças auto-imunes foi recentemente apresentada na Jornada Brasileira de Reumatologia, em Brasília. ${ }^{(1)}$

O objetivo do presente estudo é apresentar um caso de LES com plaquetopenia persistente que exigia o uso

Recebido em 15/09/05. Aprovado, após revisão, em 15/11/05

1. Núcleo de Reumatologia da Bahia, Hospital Santa Izabel (HSI), Escola Bahiana de Medicina e Saúde Pública (EBMSP)

2. Fundação Osvaldo Cruz, Laboratório de Patologia e Biologia Molecular, Fiocruz., Salvador, Bahia.

Endereço para correspondência: Mittermayer B. Santiago, Praça Almeida Couto, nº 500, Nazaré, Salvador, CEP 40000-000, Bahia, Brasil, telefone/fax (71) 3326-5276, mitter@svn.com.br 
crônico de imunossupressor e corticosteróide, para o qual foi utilizado o rituximabe (RTX), com resposta satisfatória do quadro. É apresentado também o estudo do perfil de linfócitos B e a expressão de moléculas de co-estimulação CD40 e CD80, através de citometria de fluxo, antes e após o uso da medicação.

\section{DESCRIÇÃO DO CASO}

LSST, feminino, 19 anos, em 2002, iniciou quadro de rash malar, fotossensibilidade, artrite de mãos e tornozelos, além de proteinúria nefrótica. Na avaliação diagnóstica, foi realizado FAN por imunofluorescência indireta em HEp-2, cujo resultado foi positivo, 1/640, padrão homogêneo; além da positividade dos anticorpos anti-DNA nativo. Procedeu-se à biópsia renal, a qual demonstrou glomerulonefrite membranosa. Com base nos dados clínicos e laboratoriais, foi diagnosticado LES e iniciado tratamento com corticoterapia e pulsoterapia de ciclofosfamida $\mathrm{lg}$ /dose, tendo sido realizadas seis pulsos mensais e seis trimestrais até março de 2004, com boa resposta, quando optou-se pela introdução de azatioprina $75 \mathrm{mg} /$ dia como droga de manutenção, com suspensão gradativa da prednisona. A paciente manteve-se assintomática até novembro de 2004, quando apresentou contagem de plaquetas de 52.000/ $\mathrm{mm}^{3}$, além do reaparecimento dos anticorpos anti-DNA e queda das frações do complemento. Nesta ocasião, foi aumentada a dose de azatioprina para $150 \mathrm{mg} /$ dia (peso da paciente: $67 \mathrm{Kg}$ ). Um mês depois, foi realizada nova avaliação laboratorial que revelou contagem de plaquetas de $63.000 / \mathrm{mm}^{3}$ e hemoglobina de $10,4 \mathrm{~g} / \mathrm{dl}$ com teste de Coombs direto positivo, quando foi re-introduzido 10 mg de prednisona. Após o uso do corticosteróide, houve aumento do número de plaquetas, porém o teste de Coombs direto persistia positivo. Foi aumentada a dose de prednisona para $20 \mathrm{mg} / \mathrm{dia}$, mas, em abril de 2005, voltou a apresentar plaquetopenia $\left(20.000 / \mathrm{mm}^{3}\right)$ e optou-se pelo uso do rituximabe com infusões IV de $600 \mathrm{mg} /$ dose/semana, por 4 semanas $\left(375 \mathrm{mg} / \mathrm{m}^{2} /\right.$ dose $)$, nos dias 17 , 24 e 31 de maio e 7 de junho. As infusões do rituximabe foram precedidas pelo uso de prednisona, paracetamol, prometazina e dimenidrinato. A paciente não apresentou nenhuma intercorrência durante as infusões, tendo sido realizadas as duas últimas em regime ambulatorial. Observou-se um aumento no número de plaquetas (Tabela 1) em menos de um mês após a última dose, permitindo a suspensão da azatioprina e a diminuição progressiva do corticosteróide (dose atual de prednisona: $5 \mathrm{mg} /$ dia).
TABELA 1

VARIAÇÃO DO NÚMERO DE PLAQUETAS, TÍTULO DOS ANTICORPOS ANTI-DNA E NÍVEIS DAS FRAÇÕES DO COMPLEMENTO C3 E C4, ANTES E APÓS O USO DE RITUXIMABE

\begin{tabular}{c|c|c|c|c}
\hline Data & Plaquetas/mm & Anti-DNAn & $\begin{array}{c}\text { C3 } \\
(\mathbf{7 0 - 1 7 6 )}\end{array}$ & $\begin{array}{c}\text { C4 } \\
(\mathbf{1 2 - 3 6 )}\end{array}$ \\
\hline $\begin{array}{c}31 \text { de abril } \\
\text { (antes) }\end{array}$ & 20.000 & $1 / 160$ & 55 & 8 \\
$\begin{array}{c}\text { 27 de junho } \\
\text { 11 de agosto }\end{array}$ & 194.000 & $1 / 40$ & 49 & 7 \\
\hline
\end{tabular}

PERFIL DOS LINFÓCITOS B E EXPRESSÃO DE MOLÉCULAS DE CO-ESTIMULAÇÃO POR CITOMETRIA DE FLUXO ANTES E DEPOIS DE UM MÊS DO TRATAMENTO COM RTX

Amostra de sangue coletada com EDTA foi analisada para marcadores de superfície celular com anticorpos monoclonais conjugados contra CD19, CD23, CD40 e CD80 humanos (FITC ou PE) na concentração ótima. As células foram incubadas por 30 minutos, lisadas e depois lavadas e lidas imediatamente com 30,000 eventos no citômetro de fluxo FACsort - Becton Dickinson e analisadas com um programa Cell Quest-BD. Todos os gráficos foram do tipo dot plot tamanho (FCS) vs granulosidade (SSC). A Figura 1 mostra a queda de linfócitos B e moléculas de co-estimulação após o uso de RTX.

\section{Figura 1}

ANÁLISE DE MOLÉCULAS CO-ESTIMULATÓRIAS EM SUBPOPULAÇÕES DE LINFÓCITOS B DO SANGUE PERIFÉRICO. (A)- LINFÓCITOS B CD19+ E (B)- LINFÓCITOS B CD23+ ANTES E DEPOIS DO TRATAMENTO COM RITUXIMABE A

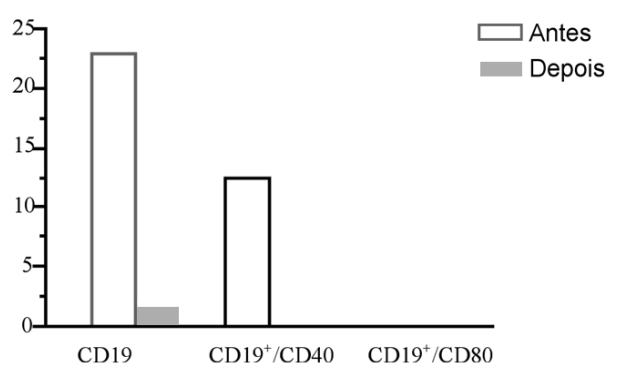

B

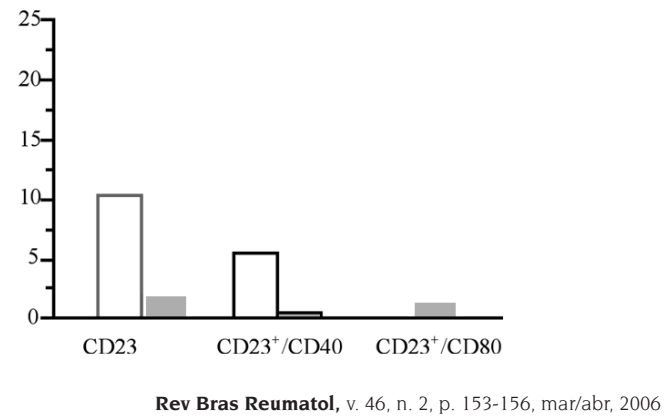




\section{DISCUSSÃO}

Nos últimos anos, o arsenal terapêutico reumatológico ganhou muita força com a introdução de medicações específicas contra citocinas, receptores celulares ou solúveis, configurando a chamada "terapia biológica". Nesse contexto citam-se as medicações anti-TNF utilizadas particularmente para artrite reumatóide, espondilite anquilosante e artrite psoriásica, tais como o infliximabe, o etanercepte e o adalimumabe ${ }^{(2,3)}$. Outras medicações que pertencem a esta família seriam o anakinra, com a sua ação contra a interleucina $\mathrm{l}^{(4)}$, o CTLA4-Ig, uma proteína de fusão inibitória da co-estimulação de linfócitos ${ }^{(5)}$ e o $\mathrm{RTX}^{(6)}$. Este último agente é um anticorpo monoclonal quimérico (IgGl) contra receptores de linfócitos $\mathrm{B}$, causando depleção dessas células por apoptose ou citotoxicidade dependente de anticorpos ou complemento. Originalmente utilizado para o tratamento de linfomas não-Hodgkin de células $\mathrm{B}$, apenas nos últimos anos o RTX passou a ser utilizado para o tratamento de doenças auto-imunes.

O primeiro relato do uso de RTX para o tratamento de plaquetopenia auto-imune foi publicado por Ratanatharathorn et $a I^{7}$, em um paciente com doença de enxerto versus hospedeiro. Posteriormente, outros autores descreveram a eficácia de tal medicação no tratamento desta complicação ${ }^{(8,9)}$.

Adicionalmente, trabalhos recentes têm confirmado o papel do RTX no tratamento de diversas manifestações do LES, com melhora nos parâmetros clínicos como artrite, serosite, alterações renais, anemia hemolítica, plaquetopenia e parâmetros sorológicos, além da melhora dos indicadores de atividade de doença, permitindo reduzir ou suspender medicações como corticosteróides e imunossupressores ${ }^{(10,11)}$.

A nossa paciente apresentava plaquetopenia que não respondia a doses de $20 \mathrm{mg} /$ dia de prednisona e uso concomitante de azatioprina. Para evitar o uso de doses altas de corticosteróides, optou-se então pela utilização de

\section{REFERÊNCIAS}

1. Lima IVS, Pallota R, Landeiro L et al: Uso de rituximabe em doenças auto-imunes. Rev Bras Reumatol 45 (suppl 1): S44, 2005.

2. Klinkhoff A: Biological agents for rheumatoid arthritis: targeting both physical function and structural damage. Drugs 64: 1267 $83,2004$.

3. Braun J, Sieper J: Biological therapies in the spondyloarthritidesthe current state. Rheumatology (Oxford) 43: 1072-84, 2004.

4. Waugh J, Perry CM. Anakinra: a review of its use in the management
RTX, com uma resposta satisfatória e a mesma encontrase atualmente com 262.000 plaquetas $/ \mathrm{mm}^{3}$ e com uma dose de prednisona de apenas $5 \mathrm{mg} /$ dia, sendo suspensa a azatioprina. Observou-se também que, além do aumento do número de plaquetas, houve aumento das frações do complemento após o uso de RTX. Por outro lado, os anticorpos anti-DNA mantiveram-se presentes, embora em títulos mais baixos, o que pode ser atribuído à falta de ação do RTX sobre os plasmócitos, que não expressam CD20.

$\mathrm{O}$ uso de RTX não foi associado a efeitos colaterais relacionados à infusão, concordando com a experiência da maioria dos autores, provavelmente porque o nosso protocolo inclui o pré-tratamento com prednisona, antihistamínico, paracetamol e dimenidrinato. Por outro lado, embora sendo um evento raro, alguns pacientes desenvolvem reação de hipersensibilidade como febre, urticária e hipotensão, como ocorreu em uma das pacientes tratadas no nosso serviço ${ }^{(1)}$.

Tem sido demonstrado o papel de moléculas de coestimulação CD40-CD40L e CD28-CD80 na ativação de linfócitos T, particularmente em pacientes com LES. Portanto, a análise da ação de medicações sobre tais moléculas torna-se relevante. Assim, no presente caso, o estudo por citometria de fluxo demonstrou uma depleção nos linfócitos $\mathrm{B}$ e uma queda no número de moléculas co-estimulatórias CD40 dos linfócitos CD19+ e CD23+, após o uso do RTX. Tal fenômeno de down-regulation dessas moléculas após RTX foi também recentemente demonstrado por Tokunaka et $a^{(12)}$, que observaram a persistência da remissão de doença em casos de LES, mesmo após o retorno ao normal dos linfócitos B, sugerindo que o RTX mantém remissão a longo prazo por corrigir a aberração das células $\mathrm{B}$.

Em conclusão, o uso de RTX em casos selecionados de LES, refratários às medidas habituais, parece ser justificado, mas faz-se necessário que estudos controlados com um número grande de pacientes sejam realizados, para que tal conduta seja definitivamente padronizada. of rheumatoid arthritis. BioDrugs 19: 189-202, 2005.

5. Ruderman EM, Pope RM: The evolving clinical profile of abatacept (CTLA4-Ig): a novel co-stimulatory modulator for the treatment of rheumatoid arthritis. Arthritis Res Ther 7(Suppl 2): S21-5, 2005.

6. Chambers SA, Isenberg D: Anti-B cell therapy (rituximab) in the treatment of autoimmune diseases. Lupus 14: 210-4, 2005

7. Ratanatharathorn V, Carson E, Reynolds C et al: Anti-CD20 chimeric monoclonal antibody treatment of refractory immunemediated thrombocytopenia in a patient with chronic graftversus-host disease. Ann Intern Med 133:275-9, 2000. 
8. Braendstrup P, Bjerrum OW, Nielsen OJ et al: Rituximab chimeric anti-CD20 monoclonal antibody treatment for adult refractory idiopathic thrombocytopenic purpura. Am J Hematol 78: 275-80, 2005.

9. Lalayanni C, Stavroyianni N, Saloum R, Tsompanakou A, Anagnostopoulos A: Rituximab is effective for selected patients with chronic steroid-refractory immune thrombocytopenic purpura. Hematology 9: 287-9, 2004.

10. Leandro MJ, Edwards JC, Ehrenstein MR, Cambridge G, Isenberg DA: B lymphocyte depletion in the treatment of systemic lupus erythematosus. Arthritis Rheum 50: S447, 2004.

11. Looney RJ, Anolik JH, Campbell D et al: B cell depletion as a novel treatment for systemic lupus erythematosus: a phase I/II dose-escalation trial of rituximab. Arthritis Rheum 50: 2580-9, 2004

12. Tokunaga M, Fujii K, Saito K et al: Down-regulation of CD40 and CD80 on B cells in patients with life-threatening systemic lupus erythematosus after successful treatment with rituximab. Rheumatology (Oxford) 44: 176-82, 2005. 